\title{
THE EFFICACY OF THE INHERENT STRAIN METHOD IN DETERMINING RESIDUAL STRESS IN IN718 SLM SPECIMENS
}

\author{
H. Botha ${ }^{1 *}$, D. Marais ${ }^{2} \&$ C.P. Kloppers ${ }^{1}$
}

\section{ARTICLE INFO}

\section{Article details}

Presented at the $22^{\text {nd }}$ Annual International Conference of the Rapid Product Development Association of South Africa (RAPDASA), held from 3-5 November 2021 in Pretoria, South Africa.

Available online 29 Nov 2021

\section{Contact details}

Corresponding author Herculaasbotha@gmail.com

\section{Author affiliations}

1 School of Mechanical Engineering, Additive Manufacturing Research Group, North West University, South Africa

2 Research and Technology Development, South African Nuclear Energy Corporation (Necsa) SOC Limited, South Africa

\section{ORCID® identifiers}

H. Botha

https://orcid.org/0000-0003-4417-9543

D. Marais

https://orcid.org/0000-0001-8952-6217

C.P. Kloppers

https://orcid.org/0000-0001-5942-0251

\section{DOI}

http://dx.doi.org/10.7166/32-3-2662

\section{ABSTRACT}

This paper presents a study showing the efficacy of the inherent strain method and modifications thereof to predict residual stresses within selective laser melted components. Cubic specimens with variations in hatch rotations were produced, and the residual stress state was simulated and measured by employing the neutron diffraction technique. Variances in the simulated and observed values of stress in the samples were investigated to show the efficacy of the isotropic, orthotropic, and thermomechanical simulation methods. The simulations indicated a suitable prediction of the residual stress with the incorporation of hatch rotation, but as being less adept at resolving the residual stress of the components with no hatch rotation. The most accurate simulation results in the horizontal stress directions were seen for the $90^{\circ}$ hatch rotation specimen, for which the average difference between the measured and simulated values were below $65 \mathrm{MPa}$ for all simulation types. The simulations largely over-predicted Z direction compressive stresses; however, the thermomechanical simulation type predicted this stress with an average difference of 116,98 , and 72 MPA for the $0^{\circ}, 67^{\circ}$, and $90^{\circ}$ hatch rotations respectively.

\section{OPSOMMING}

Hierdie artikel bestudeer die doeltreffendheid van die inherente vervormingsmetode en modifikasies daarvan om resspannings binne selektiewe, lasergesmelte komponente te voorspel. Kubusvormige monsters met variasies in luikrotasies is geproduseer, en die resspanningstoestand is gesimuleer en gemeet deur die neutrondiffraksietegniek te gebruik. Variasies in die gesimuleerde en waargenome waardes van spanning in die monsters is ondersoek om die doeltreffendheid van die isotropiese-, ortotropiese- en termomeganiese simulasiemetodes aan te toon. Die simulasies het 'n geskikte voorspelling van die resspanning met die inkorporering van luikrotasie aangedui, maar was minder geskik om die resspanning van die komponente met geen luikrotasie op te los. Die mees akkurate simulasie resultate in die horisontale spanningsrigtings is gesien vir die $90^{\circ}$-luikrotasiemonster, waarvoor die gemiddelde verskil tussen die gemete en gesimuleerde waardes onder $65 \mathrm{MPa}$ vir alle simulasietipes was. Die simulasies het Zrigting drukspannings grootliks oorvoorspel; die termomeganiese simulasietipe het egter hierdie spanning voorspel met 'n gemiddelde verskil van 116, 98 en 72 MPA vir die $0^{\circ}, 67^{\circ}$ en $90^{\circ}$ luikrotasies, onderskeidelik.

Selective laser melting (SLM) is a laser powder bed fusion process that is used to create high density, complex, and near net shape metallic parts in a process similar to micro-welding. SLM uses a laser for thermal input to melt and fuse metallic powder materials, thereby forming a component through a layerby-layer approach. SLM has shown good capabilities in producing complex components using hard to machine alloys such as Ti-6Al-4V, chromium alloys (CoCr), and nickel-based alloys such as IN625 and IN718 
[1]. As a result, this technology has been used by the dental, aeronautical, aerospace, and automotive industries.

However, the widespread adoption of SLM components has been limited, as the manufacturing process invariably leads to residual stress (RS) formation in the components. As a result, varying mechanical response, warping, and cracking have been observed in IN718-manufactured specimens [2]. These faults in turn result in the loss of component dimensional accuracy, the failure of the component, or even the failure of the SLM machine [3].

RS in SLM components is caused by the thermal input on the layer being scanned together with the heating and cooling cycle owing to subsequent layer additions [3]. Research has shown that the RS magnitude and distribution in IN718 SLM components depend on the process parameters that affect the thermal attributes during production, such as variations in the build plate temperature, deposition height, layer height, laser scan rates, and laser power [4]. With regard to the laser parameters, RS may be minimised by reducing the laser power or increasing the scan rate, thereby reducing thermal input into the component [5].

Despite the potential reduction in RS by changing these parameters, studies have shown a corresponding alteration of the mechanical properties and an inconsistent density of the as-built components [6]. Work done by Balbaa et al. revealed changes in the relative density, yield strength, and elasticity of IN718 components with different scan rates and laser powers [7]. Other studies have shown the dependence of mechanical response on layer deposition height and component build orientation $[8,9]$. To ensure the consistency of mechanical properties, these parameters must often remain unchanged once components with adequate relative density and preferential mechanical properties have been achieved.

Another process parameter that has a large effect on the RS directionality and magnitude, but with minimal effect on the mechanical properties, is the scanning strategy [10]. The scanning strategy pertains to the method by which the laser scan tracks are applied to individual layers and variations of track patterns between layers. A few commonly employed scanning strategies are shown in Figure 1.

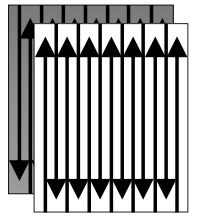

A

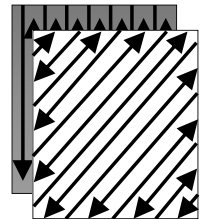

$\mathrm{B}$

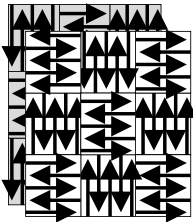

$\mathrm{C}$

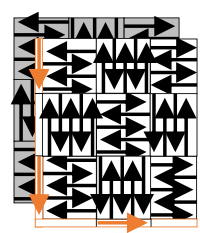

D

Figure 1: Common scanning strategies: A) bi-directional line scan; B) bi-directional line scanning with hatch rotation; $C$ ) chess board scanning; D) island scanning

RS varies directionally according to the direction of the applied scan tracks, resulting in a high RS magnitude in the scan direction, most notably where scan tracks are not rotated between layers [11, 12]. With the introduction of a rotation of scan tracks between layers, less directional RS variance has been observed, especially where scan tracks are fully perpendicular to one another [11]. A reduction of the scan track length on a cross-sectional area may also be done by using island scanning strategies; however, these have been found to lead to highly localised RS within components [2].

Since the RS developed during SLM is often near the yield strength of the produced material, simulation methods have been developed to predict the formation, magnitude, distribution, and detrimental effects of RS in SLM components. To simulate the SLM process, both micro-scale and macro-scale models have been developed.

The micro-scale models simulate the thermal interaction of the single scan tracks, multiple adjacent scan tracks, or even a few successive layers of the SLM process $[10,13]$. From this, the thermal interaction and RS can be derived for specific scan strategies. Despite the insight gained into the effects of process parameters on single scan tracks and on individual layers, these simulation types are computationally expensive owing to the small layer heights (typically 20-100 $\mu \mathrm{m}$ ), and so are not applicable to component scale geometries.

Macro-scale simulation models are a less computationally taxing approach to simulating the RS and the resultant deformation in SLM processes. Macro-scale predictions are done by simulating the individually manufactured layers in a lumped mechanical layer equivalent (MLE), often more than $10 \times$ the size of the 
layers used in manufacturing. This MLE approach is then able to determine the RS and deformation of a geometry at a component scale [14].

Using the inherent strain method (ISM) coupled with the MLE approach, RS formation may be simulated in AM processes. This form of the ISM uses strains assigned to the MLE to simulate RS build-up in a layer-bylayer fashion, with the allocated strain values being derived from micro-scale modelling of multiple layers, or more commonly through the use of deflection measurements of calibration geometries [14-16]. These models have been shown to predict component deformation accurately, with Bugatti et al. indicating a difference of only $1 \%$ on the largest deflection measurement [14]. Differences have been observed, however, between predicted and measured RS in the SLM components. These models therefore require an external validation of derived RS [17].

The experimental validation of $A M$ simulations is often done using practical RS measurements. These measurements may be either destructive or non-destructive in nature. Hole drilling and the contour method are destructive techniques that have been used in SLM RS measurements, while in situ digital imaging correlation, $x$-ray diffraction, and neutron diffraction have been used as non-destructive techniques [10, 18-20]. As this study was aimed at measuring the triaxial RS in the bulk section of a specimen nondestructively, neutron diffraction (ND) was used.

ND has been used to study the effect of build plate removal, build orientation, support structure geometry, and component geometry on RS in SLM components [12, 21]. Both thin- and thick-walled components have been investigated, with the addition of geometric stress raisers also incorporated. ND measurements are also used to validate predicted RS from simulation methods [22].

Ultimately, the purpose of this research was to determine the efficacy of the commercially developed ISM, as found in Simufact Additive, for RS prediction of Inconel 718 (IN718) components with different scanning strategies [23]. Both mechanical and thermo-mechanical configurations were applied to predict the RS state of specimens with varying process parameters. Only a variation in scanning strategy was investigated, as this plays a key role in RS magnitude and distribution, and contributes only minimally to the mechanical properties of manufactured components.

\section{SAMPLE PREPARATION}

In this study, Praxair ${ }^{\circledR}$ virgin gas atomised IN718 powder material was used to prepare the samples. The powder's extrinsic properties were analysed using scanning electron microscopy and the image-processing software ImageJ [24]. Particle D10, D50, and D90 diameters were measured as 11.73, 18.22 and $36.54 \mu \mathrm{m}$ respectively, and showed high spheroidicity.

The IN718 SLM specimens used for the calibration of the ISM and the ND measurements were manufactured using parameters supplied by ORLAS. The components were manufactured in a $99.98 \%$ nitrogen, $0.02 \%$ oxygen environment at a temperature of $34.4^{\circ} \mathrm{C}$ in an ORLAS Creator SLM machine. Layer height was set at $25 \mu \mathrm{m}$, with spot size and scan speed of $120 \mu \mathrm{m}$ and $630 \mathrm{~mm} / \mathrm{s}$ respectively. A scan speed of $220 \mathrm{~mm} / \mathrm{s}$ was applied to the perimeter scans. Laser power was set to $107 \mathrm{~W}$ for the interior regions and to $120 \mathrm{~W}$ for the perimeter scans. The processing parameters of the samples were varied only in relation to the hatch rotation (HR), with all specimens using bidirectional line scanning with a hatch spacing of $120 \mu \mathrm{m}$ on each individual layer. The scanning strategies used for the production of the specimens are shown in Figure 2. Two different geometries were produced for the study: cantilevers to calibrate the simulation methods, and cubes to measure RS using ND.

The cantilevers were cut at a height of $3.8 \mathrm{~mm}$ from the build plate, with displacement measurements taken using a micrometer, at a constant room temperature of $24^{\circ} \mathrm{C}$ at the location shown in Figure $3(\mathrm{~A})$. It was noted that an excess displacement of $120 \mu \mathrm{m}$ occurred on the outer edges of the cantilever geometries owing to the perimeter scans, as shown in Figure 3(B). This difference was subtracted from the total displacement to yield more accurate calibration results.

Using the same build parameters as the cantilevers, cube specimens with sizes of $15 \times 15 \times 15 \mathrm{~mm}^{3}$ were produced for the $0^{\circ}, 67^{\circ}$, and $90^{\circ} \mathrm{HR}$ configurations. Cylindrical supports were applied to the bottom surface of the cubes at a height of $4 \mathrm{~mm}$. The cubes were removed from the build plate at a height of 3.8 $\mathrm{mm}$ using wire EDM with a $200 \mu \mathrm{m}$ brass wire perpendicular to the $\mathrm{Y}$-axis and moving in the $+\mathrm{X}$ direction relative to the cubes shown in Figure 4. 
A)

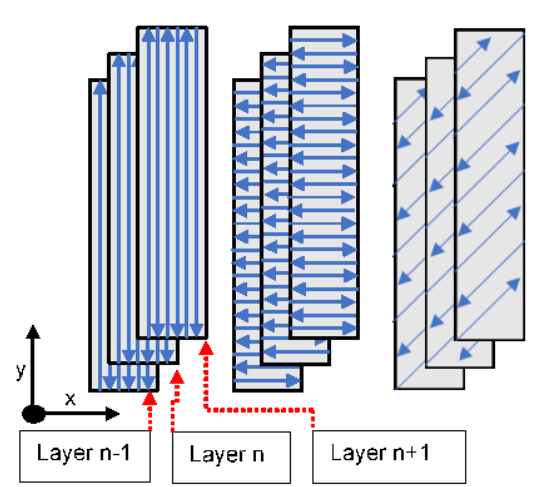

D).

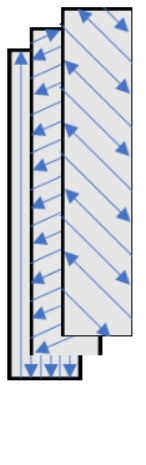

E).

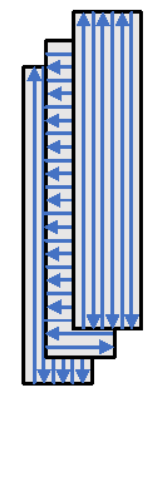

Figure 2: Scanning strategies employed for cantilever production: A) $0^{\circ} \mathrm{HR}$ longitudinal scan; B) $0^{\circ}$ HR lateral scan; C) $0^{\circ} \mathrm{HR} 45$ global rotate; D) $67^{\circ} \mathrm{HR}$; E) $90^{\circ} \mathrm{HR}$

A

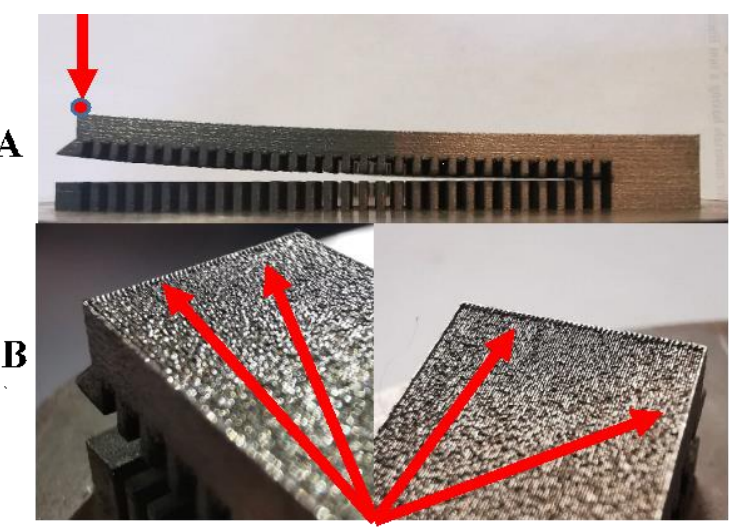

Figure 3: Cantilever geometry: A) displacement measurement point; B) perimeter scan displacement

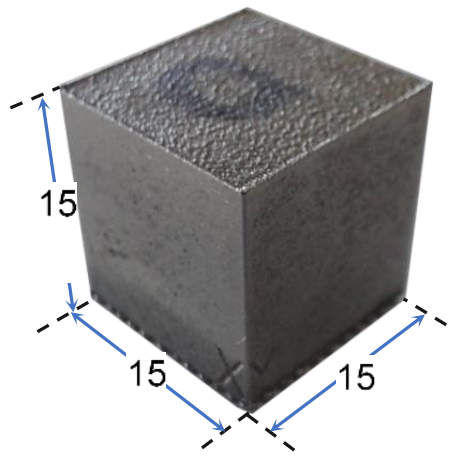

Figure 4: Cube geometry used to test residual stress

\section{INHERENT STRAIN METHOD}

The ISM determines the RS state by estimating the source of the residual stresses. In this method, the incompatible strain fields are derived by cutting the specimen, thereby changing the RS but not the strain in the component [26]. The total strain within a component can be seen as the sum of the elastic, plastic, thermal, phase change, and creep strains given in equation (1) [27].

$$
\varepsilon_{\text {total }}=\varepsilon_{\text {elastic }}+\varepsilon_{\text {plastic }}+\varepsilon_{\text {thermal }}+\varepsilon_{\text {phase }}+\varepsilon_{\text {creep }}
$$


Excluding the strains caused by phase change and creep, according to Liang et al., the mechanical ISM may be viewed as follows [28]. Assuming two points $A$ and $B$ within a solid material, the distance between the points in an unstressed and a stressed state are given by $d s_{0}$ and $d s$ respectively. When stress is relaxed by cutting or sectioning the material, this distance changes from $d s$ to $d s^{*}$. Thus the inherent strain is the residual strain in the stress relaxed state compared with the stress free state, as given in equation (2).

$$
\varepsilon^{*}=\left(d s^{*}-d s_{0}\right) / d s_{0}
$$

Since the strains are analysed after the cooling of the component, the thermal strain is not considered, with only the mechanical strains being taken into account. From this equation (2) may be rearranged as given by equation (3).

$$
\varepsilon^{*}=\left(d s-d s_{0}\right) / d s_{0}-\left(d s-d s^{*}\right) / d s_{0}
$$

Taking into consideration that $d s_{0}$ is approximately equal to $d s$, the equation takes the form given by equation (4).

$$
\varepsilon^{*}=\left(d s-d s_{0}\right) / d s_{0}-\left(d s-d s^{*}\right) / d s
$$

The first and second terms in equation (4) represent the plastic and elastic strains respectively; thus the inherent strain is given by equation (5).

$$
\varepsilon^{*}=\varepsilon_{\text {plastic }}-\varepsilon_{\text {elastic }}
$$

Viewing the elastic strains as negligible after stress relaxation, the plastic strains are used as the inherent strains that are present in the hatching area of the mechanical ISM model [14]. The thermo-mechanical ISM uses a slightly different approach from that of the mechanical ISM by taking into consideration the thermal strains as part of the inherent strain in the material, as given by equation (6).

$$
\varepsilon^{*}=\varepsilon_{\text {thermal }}+\varepsilon_{\text {plastic }}-\varepsilon_{\text {elastic }}
$$

The thermal strains are solved by coupling a thermal and a mechanical analysis. The governing equation of the thermal model is given by equation (7) [15].

$$
\rho c_{p} \frac{d T}{d t}=\frac{\partial}{\partial x}\left(k \frac{\partial T}{\partial x}\right)+\frac{\partial}{\partial y}\left(k \frac{\partial T}{\partial y}\right)+\frac{\partial}{\partial z}\left(k \frac{\partial T}{\partial z}\right)+Q
$$

where $\rho(\mathrm{g} / \mathrm{cm})$ is the material density, $c_{p}\left(\mathrm{~J} \mathrm{Kg}^{-1} \mathrm{~K}^{-1}\right)$ the temperature dependent specific heat capacity, $T$ (K) the temperature, $k\left(\mathrm{~W} \mathrm{M}^{-1} \mathrm{~K}^{-1}\right)$ the temperature-dependent thermal conductivity, and $Q\left(\mathrm{~J} \mathrm{M}^{-3}\right)$ the volumetric heat flux. The volumetric heat flux may then be correlated with the laser parameter through equation (8).

$$
Q=(\eta * P) /(v * h * t)
$$

where $\eta(\%)$ denotes laser efficiency and $P(\mathrm{~W})$ the laser power, $v(\mathrm{~mm} / \mathrm{s})$ the scan speed, $h(\mathrm{~mm})$ the hatch distance, and $t(\mathrm{~mm})$ the layer height. Using conductive boundary conditions on the build plate, with convective and radiative boundary conditions on the component surfaces, a temperature field within the component is derived; from this the temperature-dependent thermal expansion factor can be determined through equation (9).

$$
\varepsilon_{\text {Thermal }}=\alpha(T) \Delta T
$$

\subsection{Mechanical inherent strain method calibration}

The mechanical ISM in Simufact Additive supports isotropic and orthotropic solution types, and requires calibration values obtained from cantilever calibration samples. The mechanical ISM models used $0.25 \mathrm{~mm}$ uniform voxels for the cantilevers and $0.5 \times 0.5 \times 3 \mathrm{~mm}^{3}$ voxels for the build plate. The material properties of the cantilevers and the build plate were taken as given in Simufact for IN718 and CR45 respectively.

The isotropic calibration used a single cantilever geometry to determine a uniform $X$ and $Y$ direction inherent strain for the applied production parameters. For this, three calibrations were done: of the $0^{\circ}$ longitudinal, $67^{\circ}$, and $90^{\circ} \mathrm{HR}$ configurations using corresponding cantilevers. 
For the orthotropic ISM, calibration requires the use of two cantilevers - namely, $0^{\circ}$ longitudinal and $0^{\circ}$ lateral scanned cantilevers. In this way, differing inherent strains are solved for the $X$ and $Y$ directions. These inherent strain values may then be rotated between layers of elements to simulate the effects of hatch rotation.

\subsection{Thermo-mechanical inherent strain method calibration}

The thermo-mechanical calibration in Simufact Additive is applied in two steps: a first thermal calibration is done to determine an energy exposure fraction, followed by a full thermo-mechanical calibration to determine an isotropic volumetric expansion factor. For the thermal calibration, a cantilever specimen is thermally modelled on the build plate in a layer-by-layer fashion, with the calibration target being the peak temperature experienced by the melt pool and specified at the top centre of the cantilever geometry.

From this calibration type, an energy exposure fraction is derived, describing the amount of thermal input from the laser going to melt the powder material and the amount being lost to heating adjacent powder materials. With this calculated parameter, the thermo-mechanical method is calibrated in the same way as the isotropic ISM, using single cantilever deflections to calibrate a set of manufacturing parameters and to derive a corresponding volumetric expansion factor.

The thermal and thermo-mechanical calibrations used a voxel size of $0.25 \times 0.25 \times 0.25 \mathrm{~mm}^{3}$ for the cantilevers, with a voxel size of $0.5 \times 0.5 \times 3 \mathrm{~mm}^{3}$ being chosen for the build plate as used by mechanical ISMs. The initial temperatures of the build plate and powder were taken as $25{ }^{\circ} \mathrm{C}$, with a build volume temperature of $34.4{ }^{\circ} \mathrm{C}$. An eight-second cool- down period was specified between the completion of one layer and the addition of the next, with the laser power and efficiency taken as $107 \mathrm{~W}$ and $30 \%$ respectively. Using these inputs, the thermal calibration yielded an exposure energy fraction of $33.501 \%$ for the model when using a calibration target temperature of $2000^{\circ} \mathrm{C}$. Applying this in the thermo-mechanical calibration, the deflections of the $0^{\circ}$ longitudinal, $67^{\circ} \mathrm{HR}$, and $90^{\circ} \mathrm{HR}$ cantilevers were used as calibration targets.

\subsection{Cube specimen simulation}

Using the inherent strains and volumetric expansion factors from the mechanical and thermo-mechanical calibrations, cube specimens were simulated for the $0^{\circ}$ longitudinal and the $67^{\circ}$ and $90^{\circ} \mathrm{HR}$ strategies, using the three types of ISM in Simufact. Care was taken to keep all simulation parameters constant between the calibrations and the corresponding simulations - i.e., the voxel sizes, material properties, and build parameters. This was done because the calibrated inherent strains, exposure energy fraction, and volumetric expansion factors were dependent on voxel size, material property, and process parameter usedin the calibrations and simulations [29].

The cubes of $15 \times 15 \times 15 \mathrm{~mm}^{3}$ were simulated with a support height of $4 \mathrm{~mm}$ from the build plate. The supports were specified as $80 \%$ material density in a voxel, helping to simulate the effect using cylindrical supports that did not form a fully dense structure beneath the component. Cutting of the cubes from the build plate was specified as $3.8 \mathrm{~mm}$ from the build plate and the support structure interface, with the allocated directional cutting in three steps to depict the stress relaxation that would occur during the process. The results of the RS of the $90^{\circ} \mathrm{HR}$ cube specimen on a central plane at $\mathrm{Y}=7.5 \mathrm{~mm}$ are shown in Figure 5 for the thermo-mechanical ISM, with a similar distribution seen for the other HRs and simulation types.

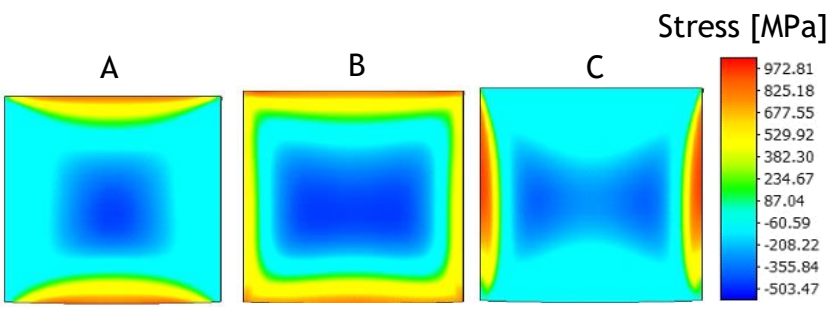

Figure 5: Central plane residual stress derived from thermo-mechanical simulations for A) $\sigma_{\mathrm{xx}} ; \mathrm{B}$ ) $\sigma_{\mathrm{yy}}$; and C) $\sigma_{\mathrm{zz}}$

\section{NEUTRON DIFFRACTION RESIDUAL STRESS MEASUREMENTS}

The practical measurement of RS using ND was done by the South African Nuclear Energy Corporation (NECSA) at the South African Fundamental Atomic Research Installation 1 (SAFARI-1) reactor using the 
Materials Probe for Internal Strain Investigations (MPISI) diffractometer [30]. These measurements were used to describe the formation of the RS in the cube specimens, and to assess the efficacy of the simulation methods of Simufact Additive.

A nominal wavelength of $1.647338 \AA$ was implemented using the Si monochromator (311) crystal plane. As IN718 is an FCC material, use was made of the $\gamma(311)$ plane because it would allow for a diffraction $2 \theta$ angle of $98.6^{\circ}$, which would result in a close-to-rectangular gauge volume [21]. The primary and secondary slit sizes were set at $2.0 \times 2.0 \mathrm{~mm}^{2}$, with a resulting instrumental gauge volume of $2.2 \times 3.17 \times 1.87 \mathrm{~mm}^{3}$ dictating that measurements be at least $1.83 \mathrm{~mm}$ from the surface for a fully submerged gauge volume (Figure 6(A)). Positional accuracy of $\pm 17 \mu \mathrm{m}$ was established, and measurement times were adjusted to obtain a targeted maximum error of $\pm 55 \mu$ strain. For the determination of the $d_{0}$ stress free lattice spacing, reference cubes were removed from an extra set of cube specimens manufactured using the $0^{\circ}$ longitudinal and the $67^{\circ}$ and $90^{\circ} \mathrm{HR}$ configurations. The reference cubes were removed from their parent samples at the locations indicated in Figure 6(C), using wire EDM to ensure that no thermal input could cause a change in microstructure. Unfortunately, the reference sample's orientation was not maintained after cutting, although the reference specimens' locations were .

A
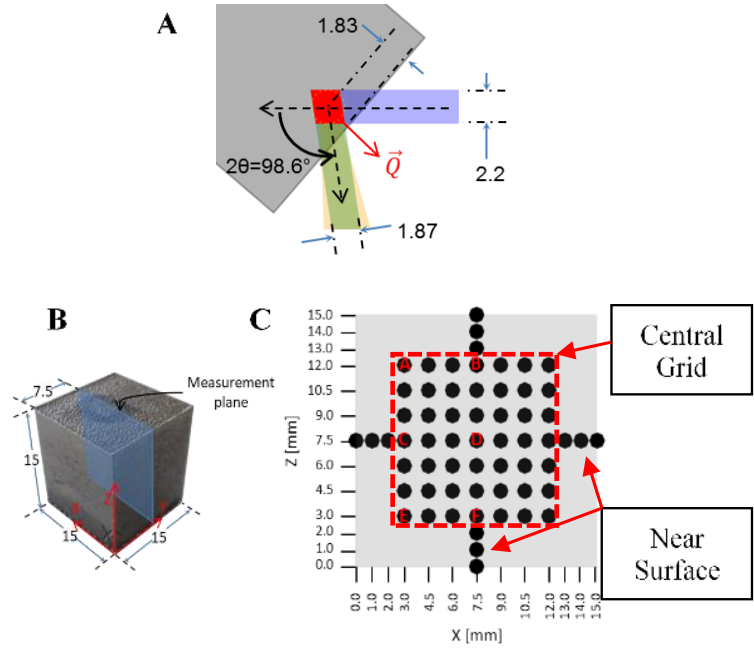

Figure 6: A) neutron diffraction gauge volume; B) diffraction measurement plane; and C) diffraction measurement and $d_{0}$ reference sample locations

The resultant $d_{0}$ lattice spacings of the reference cubes were used to determine the stress at corresponding measurement locations. These ND measurements were done on the central plane at $Y=7.5 \mathrm{~mm}$ within the cube specimen at the locations indicated in Figure $6(\mathrm{~B}$ and $\mathrm{C})$. Central grid measurements were taken at 3 $\leq X \leq 12 \mathrm{~mm}$ and $3 \leq Z \leq 12 \mathrm{~mm}$ in $1.5 \mathrm{~mm}$ increments to yield a $7 \times 7$ grid on the $X Z$ plane. Further measurements on the $X Z$ plane were taken near the surface at $X=7.5 \mathrm{~mm}$ and $Z=7.5 \mathrm{~mm}$ in $1 \mathrm{~mm}$ increments, and are referred to as 'near surface' measurements.

The resultant diffraction intensities for the $d_{0}$ and cube measurements were fitted to a Gaussian function to determine the diffraction angle. From this, the use of Bragg's law, given by equation (10), yielded the interplanar lattice spacing $\left(d_{h k l}\right)$ with the known incident wavelength $(\lambda)$ and diffraction angle $\left(2 \theta_{h k l}\right)$.

$$
\lambda=2 d_{h k l} * \sin \Theta_{h k l}
$$

Using this, the strain was derived at the measurement location using equation (11), in which $d_{i, h k l}$ and $d_{i, 0, h k l}$ denote the directional lattice spacing of the sample and the reference sample respectively.

$$
\varepsilon_{l, h k l}=\left(d_{i, h k l}-d_{i, 0, h k l}\right) / d_{i, 0, h k l}
$$

From this, the principal axes RS was determined through the use of Hooke's law, equation (12).

$$
\sigma_{i}=\frac{E}{1+v} \varepsilon_{i, h k l}+\frac{v E}{(1+v)(1-2 v)}\left(\varepsilon_{x}+\varepsilon_{y}+\varepsilon_{z}\right) \text { for } i=x, y, z
$$


where $\sigma_{i}(\mathrm{MPa})$ is the principal stress calculated for the specified direction, $E(\mathrm{GPa})$ is the modulus of elasticity of material at room temperature, $v$ is the Poison's ratio of the material, and $\varepsilon_{i}$ is the elastic strain from the lattice spacing.

\section{RESULTS}

\subsection{Inherent strains calibration}

The results of the cantilever deflections, inherent strains, and volumetric expansion factors are shown in Table 1. Corresponding with the increased deflection, both the inherent strain and volumetric expansion factors showed increases in value.

Table 1: Simulation calibration results

\begin{tabular}{|c|c|c|c|c|}
\hline Type & $\begin{array}{l}\text { Hatch rotation } \\
{\left[{ }^{\circ}\right]}\end{array}$ & $\begin{array}{l}\text { Calibrated strain } \\
\text { or volumetric } \\
\text { expansion* }\end{array}$ & $\begin{array}{l}\text { Deflection } \\
{[\mathrm{mm}]}\end{array}$ & $\begin{array}{l}\text { Deviation } \\
\text { [\%] }\end{array}$ \\
\hline \multirow{3}{*}{ Isotropic } & 0 longitudinal & -0.00616942 & 3.09 & 0.097 \\
\hline & 67 & -0.00395685 & 2.662 & 0.977 \\
\hline & 90 & -0.0029953 & 2.213 & 0.136 \\
\hline \multirow[b]{3}{*}{ Orthotropic } & 0 longitudinal & -0.00690674 & 3.068 & 0.615 \\
\hline & 0 lateral & -0.00090271 & 1.498 & 0.067 \\
\hline & 45 global & $\begin{array}{lc}\epsilon_{x x} & : \\
0.0069067 \\
\epsilon_{y y} \quad: \\
0.0009027\end{array}$ & $\begin{array}{l}\text { Tip 1: } 1.63 \\
\text { Tip 2: } 2.70\end{array}$ & $\begin{array}{l}\text { Tip 1: } \\
2.976 \\
\text { Tip 2: } \\
0.9174\end{array}$ \\
\hline \multirow{3}{*}{$\begin{array}{l}\text { Thermo- } \\
\text { mechanical }\end{array}$} & 0 longitudinal & $0.9199^{*}$ & 3.067 & 0.65 \\
\hline & 67 & $0.60^{*}$ & 2.220 & 0.18 \\
\hline & 90 & $0.3250^{*}$ & 2.67 & 0.67 \\
\hline
\end{tabular}

\subsection{Cube specimens' measured residual stress}

The results of the central grid region RS for the three HRs under investigation, measured using ND, are shown in Figure 7. The measurements of the specimens showed a trend of compressive RS at the central regions of the cubes. with a steep gradient towards tensile stress at the upper and lower regions for the $\sigma_{y y}$ and $\sigma_{z z}$ RS's, with the $\sigma_{x x}$ RS showing an added trend of increasing RS towards the left and right side of the central measurement grid, as shown in Figure 7. From these results, a large tensile RS is expected to occur towards the regions $X \geq 3 \mathrm{~mm}$ from the surface of the specimen. This tensile RS was made apparent in the near-surface RS measurements, shown in Figure 8(A), for the line parallel to the build direction at $X$ $=7.5 \mathrm{~mm}, \mathrm{Y}=7.5 \mathrm{~mm}$, and $0<\mathrm{Z}<15 \mathrm{~mm}$, and the line perpendicular to the build direction at $0<\mathrm{X}<15$ $\mathrm{mm}, \mathrm{Y}=7.5 \mathrm{~mm}$, and $\mathrm{Z}=7.5 \mathrm{~mm}$ (Figure 8(B)).

The measured $\mathrm{RS}$ on the vertical line at $\mathrm{X}=7.5 \mathrm{~mm}$ (parallel to the build direction) showed a large increase of tensile RS towards the outer surfaces of the cubes for $\sigma_{x x}, \sigma_{y y}$, and $\sigma_{z z}$. A minimal difference was observed between the RS magnitude of the different HRs for $\sigma_{x x}$ at both the centre and the outer regions of the cubes. For the $\sigma_{y y} \mathrm{RS}$ the $0^{\circ} \mathrm{HR}$ indicated the lowest magnitude for both the compressive central regions and the tensile outer regions of the specimen, compared with the specimen with HR. This was caused by the RS's dependence on scan track length, with the scan tracks in this case being parallel to the $\sigma_{x x}$ direction and correspondingly causing larger stresses in that direction. For the specimen with applied HR, the $\sigma_{\mathrm{xx}}$ and $\sigma_{\mathrm{yy}} \mathrm{RS}$ at $\mathrm{Z} \leq 3 \mathrm{~mm}$ and $\mathrm{Z} \geq 12 \mathrm{~mm}$ were all tensile in nature; however, it was seen that the RS was approximately $250 \mathrm{MPa}$ lower at the bottom edges of the specimens; this was attributed to the stress relaxation that may have occurred during removal from the build plate. 

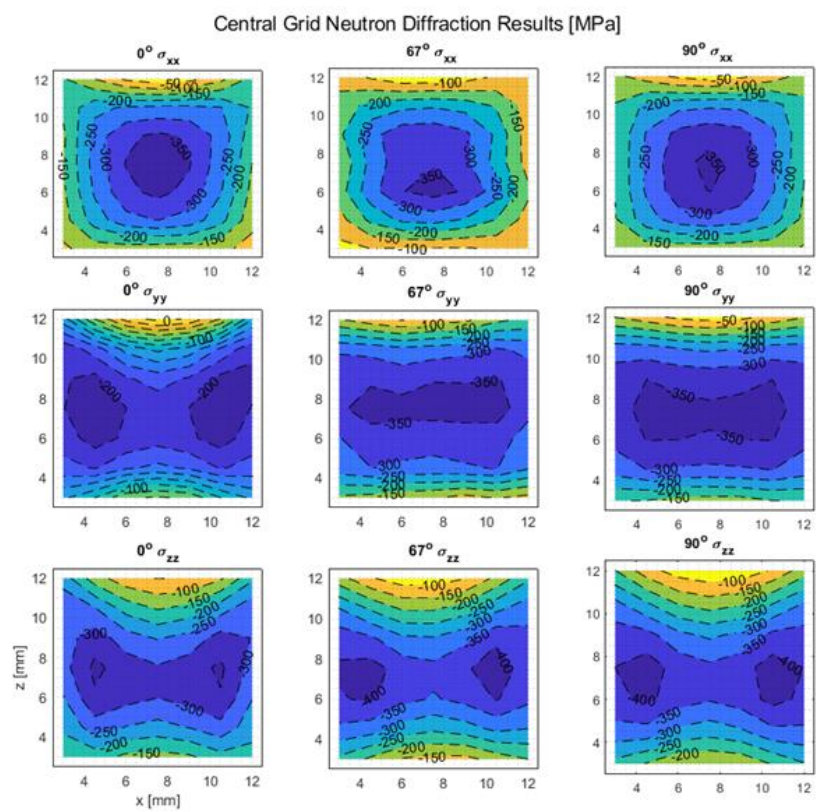

Figure 7: Neutron diffraction results for central measurement grid.
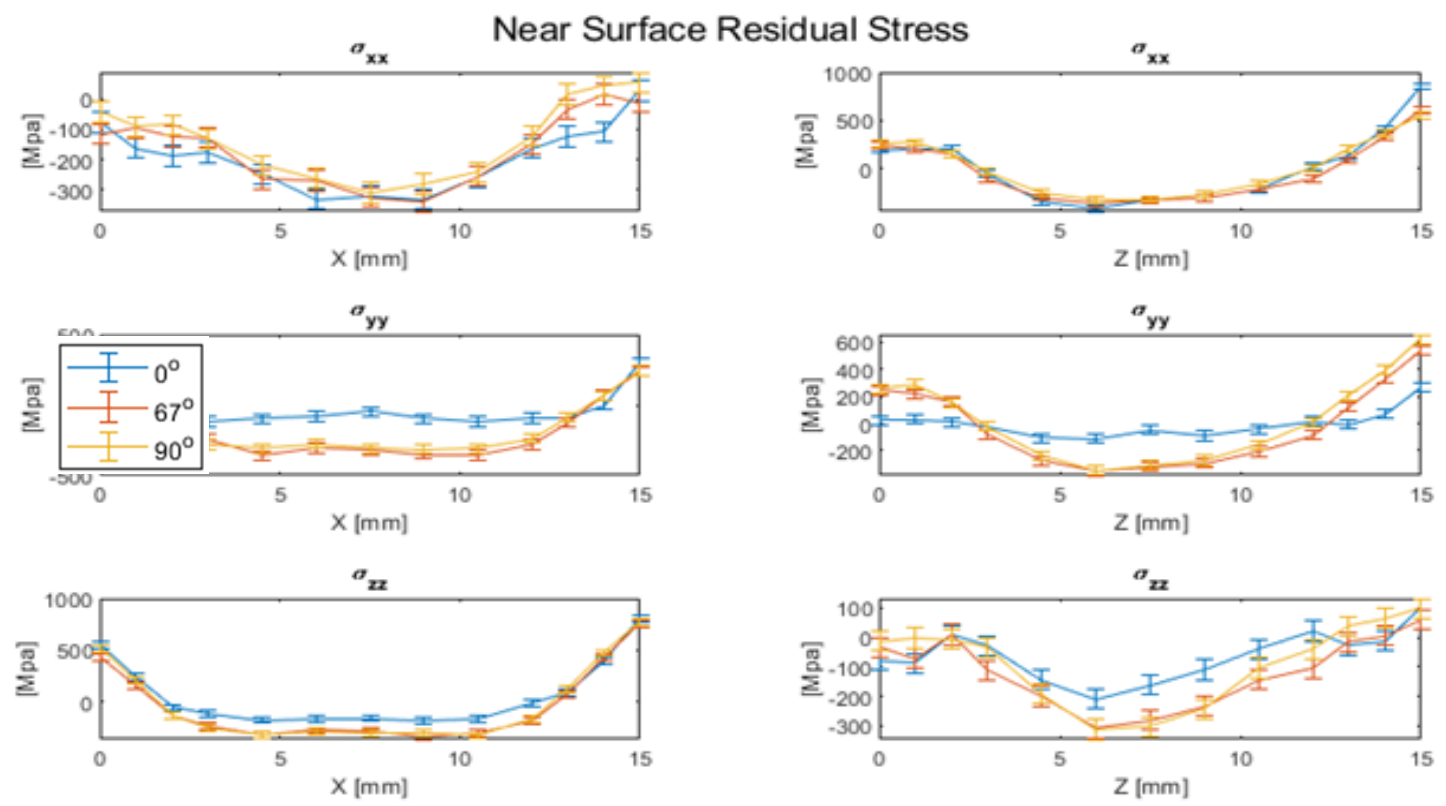

Figure 8: Neutron diffraction results for lines containing near surface measurements at $A) X=7.5$ $\mathrm{mm}, Y=7.5 \mathrm{~mm}, 0<Z<15 \mathrm{~mm}$; and $B) 0<X<15 \mathrm{~mm}, Y=7.5 \mathrm{~mm}$, and $Z=7.5 \mathrm{~mm}$

The measured $\mathrm{RS}$ on the horizontal line at $\mathrm{Z}=7.5 \mathrm{~mm}$ (perpendicular to the build direction) indicated again the compressive RS in the central regions, changing towards tensile RS at the outer edges of the specimens. For all applied HRs, the $\sigma_{x x}$ were compressive with the exception of the measurements taken on the outer edge towards $X=15 \mathrm{~mm}$; but even at this location the RS measured was well below $100 \mathrm{MPa}$. In comparison, the $\sigma_{\mathrm{yy}} \mathrm{RS}$ showed much larger tensile RS toward the outer surfaces at $X<1 \mathrm{~mm}$ and $X>14 \mathrm{~mm}$. For the measurements taken at $X \leq 2 \mathrm{~mm}$ and $X \geq 13 \mathrm{~mm}$, a minimal difference in the $\sigma_{y y}$ RS was seen between the various HRs; however, the $0^{\circ} \mathrm{HR}$ indicated again a much lower compressive RS towards the central regions, with no significant difference between the $67^{\circ}$ and $90^{\circ}$ HRs throughout. Another prominent trend of the RS for the $\sigma_{\mathrm{xx}}, \sigma_{\mathrm{yy}}$, and $\sigma_{\mathrm{zz}}$ was a lowered tensile stress on the left side of the specimens at $X \leq 2 \mathrm{~mm}$ compared with the measurements taken on the right side at $X \geq 14 \mathrm{~mm}$. This was again attributed to the stress 
relaxation from the directional cutting that was used to remove the components from the build plate with a cut direction along the $X$-axis from $X=0 \mathrm{~mm}$ towards $X=15 \mathrm{~mm}$.

The resultant maximum and minimum RS measured for both the central grid region and the near-surface measurements are shown in Table 2 for the different HRs.

Table 2: Minimum and maximum measured residual stress

\begin{tabular}{|c|c|c|c|}
\hline \multirow{2}{*}{$\begin{array}{l}\mathrm{HR} \\
{\left[{ }^{\circ}\right]}\end{array}$} & \multicolumn{3}{|c|}{ All stress values in $\mathrm{MPa}$} \\
\hline & X-normal $\left(\sigma_{x x}\right)$ & Y-normal $\left(\sigma_{\mathrm{yy}}\right)$ & Z-normal $\left(\sigma_{\mathrm{zz}}\right)$ \\
\hline 0 & $\begin{array}{l}\text { Max: } 851 \\
\text { Min: }-381.35\end{array}$ & $\begin{array}{l}\text { Max: } 263 \\
\text { Min: }-215.70\end{array}$ & $\begin{array}{l}\text { Max: } 803 \\
\text { Min: }-361.64\end{array}$ \\
\hline 67 & $\begin{array}{l}\text { Max: } 605 \\
\text { Min: }-370.38\end{array}$ & $\begin{array}{l}\text { Max: } 538 \\
\text { Min: }-377.5\end{array}$ & $\begin{array}{l}\text { Max: } 748 \\
\text { Min: }-431.87\end{array}$ \\
\hline 90 & $\begin{array}{l}\text { Max: } 557 \\
\text { Min: }-361.48\end{array}$ & $\begin{array}{l}\text { Max: } 622 \\
\text { Min: }-365.91\end{array}$ & $\begin{array}{l}\text { Max: } 775 \\
\text { Min: }-424.88\end{array}$ \\
\hline
\end{tabular}

\section{COMPARISON OF SIMULATED RESULTS}

Comparing the measured and simulated RS was done in two parts: an investigation of the RS observed in the ND central grid region, and a comparison of results on the lines containing the near-surface measurements.

\subsection{Central grid results comparison}

The predicted RS values were placed in a point cloud format correlating with the nodes from the simulation in Simufact. As steep RS gradients in short distances (i.e., $x=2 \mathrm{~mm}$ ) were seen from the neutron diffraction measurements, the averaged values of the RS at nodes near the ND measurement locations were used, corresponding to a rectangular gauge volume of $1.5 \times 2.0 \times 1.5 \mathrm{~mm}^{3}$. From this, the results were applied to uniform grids corresponding with the ND central grid locations. Using these grids, the differences between the simulated and the measured stress values were determined and placed in contour plots to observe where the simulations deviated from the measured values. Since the measured RS in the central grid measurements was almost exclusively compressive, positive stress differences indicated an underprediction of the compressive RS, with negative differences indicating an over-prediction of the compressive RS.

For the stress difference contour given in Figure 9, the simulations of the cube with no hatch rotation showed a tendency to predict too high a stress at the top centre of the cubes, and too low a stress towards the bottom surfaces for the $\sigma_{\mathrm{xx}}$ RS. Furthermore, the simulation types' maximum and minimum RS differences were very nearly the same. However, the average absolute differences indicated that the thermo-mechanical simulation most accurately determined the overall distribution of the $\sigma_{\mathrm{xx}} \mathrm{RS}$ on the central measurement grid.

The $\sigma_{\mathrm{yy}}$ RS was largely over-predicted by the isotropic and thermo-mechanical ISMs. This was expected, as this component's RS was strongly influenced by scan track length, and so would require different inherent strains or volumetric expansion factors to determine adequately the RS parallel and perpendicular to the scan tracks. For this stress direction, only the orthotropic simulation type was able to determine the values to an average absolute stress difference of less than $100 \mathrm{MPa}$ throughout the central grid region. The minimum stress differences were observed in the centre of the cubes, with an over-prediction of the compressive RS towards the outer surfaces. From this it could be assumed that the inherent strain that was allocated parallel to the $\mathrm{Y}$-axis and derived from the laterally scanned cantilever was too large. 

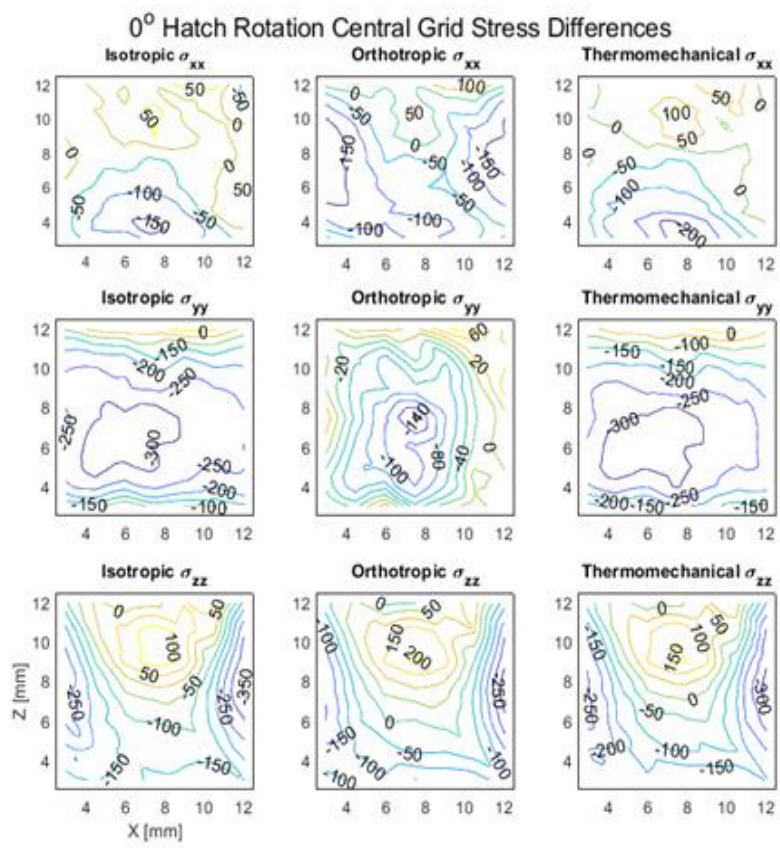

Figure 9: Stress differences of central grid measurement region for $0^{\circ}$ hatch rotation specimen
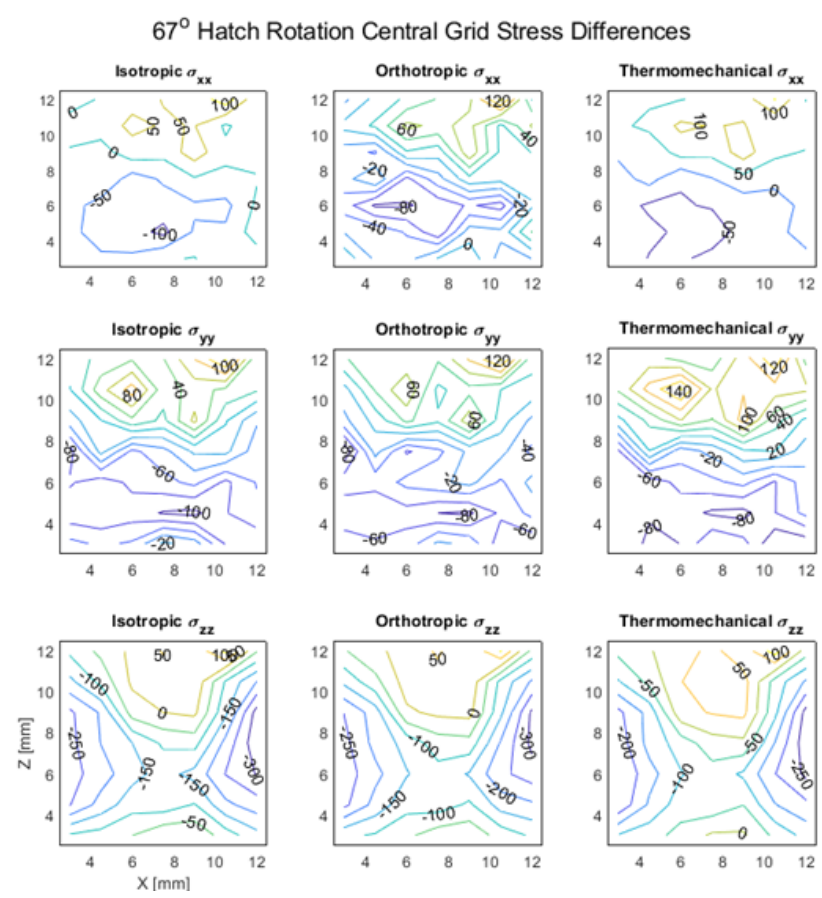

Figure 10: Stress differences of central grid measurement region for $67^{\circ}$ hatch rotation specimen

With the incorporation of hatch rotation, the cube specimen RS behaved in a transversely isotropic manner. This can be seen in the good agreement of both the isotropic and the thermo-mechanical simulations in relation to the $\sigma_{x x}$ and $\sigma_{y y}$ RS (shown in Figure 10) for the $67^{\circ} \mathrm{HR}$ (the $90^{\circ} \mathrm{HR}$ results were excluded owing to their similarity with the $67^{\circ} \mathrm{HR}$ results). The averaged absolute errors of the simulations' types also decreased by up to $162 \mathrm{MPa}$ and $111 \mathrm{MPa}$ for the thermo-mechanical and isotropic $\sigma_{\mathrm{yy}}$ values respectively. Both samples with applied hatch rotations had a very similar distribution of RS differences from the ND values. For $\sigma_{\mathrm{xx}}$ and $\sigma_{\mathrm{yy}}$, the simulations were prone to an over-prediction of the compressive RS towards the bottoms of the cubes, with under-predicted compressive values as the height increased beyond $\mathrm{Z} \approx 7.5 \mathrm{~mm}$. The $\sigma_{\mathrm{zz}}$ values again indicated the largest differences for the central grid measurements, and displayed 
almost exactly the same distribution as the specimen with $0^{\circ} \mathrm{HR}$, with arbitrary differences between the averaged stress differences (Table 3 ).

Despite the relatively poor estimation of the $\sigma_{z z}$ RS in the cubes, it can be seen that the simulations' results were more accurate with the incorporation of the hatch rotation. The different ISM simulations were not well-suited to determining the RS as found in the $\sigma_{z z}$ direction in the central grid regions of the specimen. However, by using a $90^{\circ} \mathrm{HR}$ during manufacturing, this averaged stress difference could be reduced to less than $100 \mathrm{MPa}$, indicating that, although some localised RS was being poorly estimated, the overall RS distribution in this region was relatively accurate. The minimum stress differences perpendicular to the build direction were also seen to be greatly reduced when HR was incorporated, but at the expense of an increased maximum RS difference. However, the increases in the maximum differences were slight when compared with the improved results.

\subsection{Near-surface result comparison}

As the central grid measurements were predominantly compressive, it was necessary to observe the RS towards the outer regions of the cubes, where high-tensile RS was to be expected. Observing the measured RS on the line perpendicular to the build plate at $Z=7.5 \mathrm{~mm}$ and the line parallel to the build plate at $X=$ $7.5 \mathrm{~mm}$ indicated the changes from compressive to tensile RS, and the suitability of the simulations in determining this distribution.

As can be seen from the measurements taken on the near-surface lines of the sample with $0^{\circ} \mathrm{HR}$ (Figure 11), the orthotropic ISM was best-suited to determining the RS towards the centre of the cube, with a large deviation towards the outer surfaces on the horizontal line; in this case, both the isotropic and the thermomechanical ISMs yielded better results within $1 \mathrm{~mm}$ of the surface, where large tensile RS could be found. Observing the RS results on the vertical line at $X=7.5 \mathrm{~mm}$ and $0 \leq Z \leq 15 \mathrm{~mm}$, the orthotropic ISM was only superior in determining the RSs perpendicular to the scan tracks $\left(\sigma_{\mathrm{yy}}\right)$, with a reduced efficacy of the $\sigma_{\mathrm{xx}}$ stress prediction.

\section{$0^{\circ}$ Hatch Rotation, Near Surface Results}
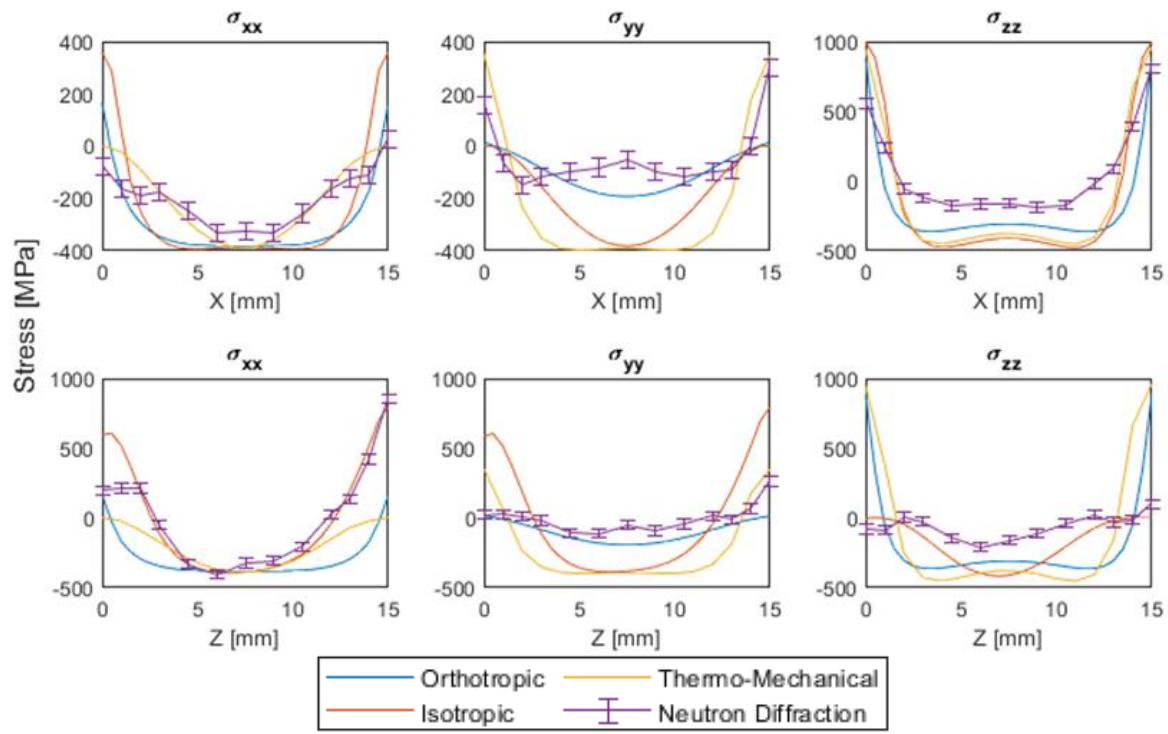

Figure 11: Near-surface residual stress results on vertical lines at $X=7.5 \mathrm{~mm}$ and horizontal lines at $\mathrm{Z}=7.5 \mathrm{~mm}$ for $0^{\circ}$ hatch rotation 


\section{$67^{\circ}$ Hatch Rotation, Near Surface Results}
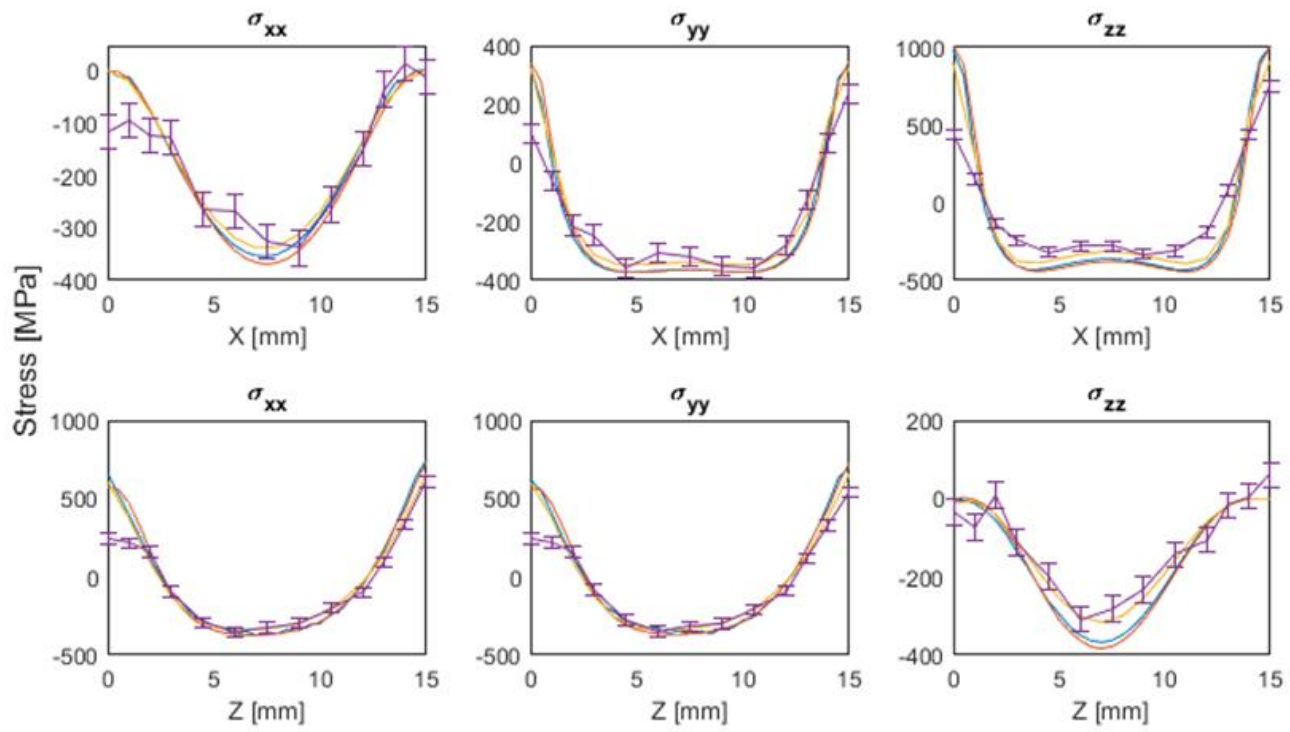

$\begin{array}{ll}\text { Orthotropic } & \text { Thermo-Mechanical } \\ \text { Isotropic } & \text { Neutron Diffraction }\end{array}$

Figure 12: Near-surface residual stress results for $67^{\circ}$ hatch rotation

With the incorporation of hatch rotation, the difference between the measured and the simulated RS again decreased for all simulation types towards the surfaces; both the horizontally and the vertically measured lines had good fit to the ND-measured RS, as shown in Figure 12 for the $67^{\circ} \mathrm{HR}$ specimen (the results of the $90^{\circ} \mathrm{HR}$ specimen are again excluded owing to their similarity with the $67^{\circ} \mathrm{HR}$ results).

Table 3: Minimum, maximum and average absolute stress differences between simulated and measured RS

\begin{tabular}{|c|c|c|c|c|c|c|c|c|c|c|}
\hline & \multicolumn{3}{|c|}{$0^{\circ}$ hatch rotation $[\mathrm{MPa}]$} & \multicolumn{3}{|c|}{$67^{\circ}$ hatch rotations [MPa] } & \multicolumn{3}{|c|}{$90^{\circ}$ hatch rotations [MPa] } \\
\hline & & $\sigma_{x x}$ & $\sigma_{\mathrm{yy}}$ & $\sigma_{\mathrm{zz}}$ & $\sigma_{\mathrm{xx}}$ & $\sigma_{y y}$ & $\sigma_{\mathrm{zz}}$ & $\sigma_{\mathrm{xx}}$ & $\sigma_{\mathrm{yy}}$ & $\sigma_{\mathrm{zz}}$ \\
\hline \multirow{3}{*}{$\begin{array}{l}\text { Isotropic } \\
\text { ISM }\end{array}$} & Min & -165 & -337 & -356 & -118 & -119 & -335 & -120 & -128 & -294 \\
\hline & Max & 75 & 18 & 134 & 130 & 123 & 116 & 74 & 67 & 40 \\
\hline & Average* & 42 & 231 & 126 & 40 & 56 & 131 & 31 & 39 & 105 \\
\hline \multirow{3}{*}{$\begin{array}{l}\text { Orthotropic } \\
\text { ISM }\end{array}$} & Min & -185 & -143 & -284 & -95 & -101 & -316 & -155 & -162 & -319 \\
\hline & Max & 108 & 70 & 211 & 126 & 124 & 105 & 38 & 49 & 36 \\
\hline & Average* $^{*}$ & 77 & 46 & 89 & 34 & 45 & 124 & 51 & 62 & 132 \\
\hline \multirow{3}{*}{$\begin{array}{l}\text { Thermo- } \\
\text { mechanical } \\
\text { ISM }\end{array}$} & Min & -228 & -331 & -323 & -98 & -111 & -282 & -125 & -131 & -235 \\
\hline & Max & 108 & 17 & 159 & 152 & 142 & 125 & 121 & 110 & 109 \\
\hline & Average* & 54 & 224 & 116 & 48 & 62 & 98 & 47 & 54 & 72 \\
\hline
\end{tabular}

It was seen that the stresses towards $X \leq 3 \mathrm{~mm}$ were largely over-predicted by the simulations, owing to the directional cutting not being properly addressed - or potentially because of the starting point of the layer scanning affected the RS distribution, as described by Bartlett et al. [20]. Should the cause of these stress differences be the scan track deposition pattern, the ISMs would be unable to account for them better, since a full layer of elements is applied instantaneously during these simulations, with all of the elements using the same inherent strains throughout the layer. It should be stated, however, that these differences are not significant because they over-predict the tensile RS that would typically induce component failure; thus the possibility of not predicting cracking during manufacturing is slight.

\section{CONCLUSION}

This paper presented the ISM applied in both mechanical and thermo-mechanically coupled variations. Using cantilever geometries, the inherent strains and volumetric expansion factors were derived for the hatch rotations under investigation. Using these calibrated models for their corresponding SLM parameters, 
the RS was determined for cube specimen geometries. Comparing these results with experimentally measured values indicated the efficacy of the simulations in predicting the RS on the specified measurement plane. The study showed that the most effective use of the inherent strain method in determining residual stress was found in thermo-mechanically coupled versions of the inherent strain method, in which the thermal distribution determines the temperature-dependent expansion and contraction of the elements that are used, compared with the constant elemental inherent strains used in mechanical approaches. From the experimentally measured results and the comparison with the simulated results, the conclusions of this work are summarised as follows:

- $\quad$ Minimal differences between stress magnitude and distribution are observed for samples with applied $\mathrm{HR}$. The use of hatch rotation also causes the directional RS variance to decrease, although at the cost of an increased overall stress magnitude. This effect is primarily caused by the length of the scan tracks and the variations in these because of hatch rotation.

- The orthotropic simulation type is the only model that accurately predicts the RS of the specimen produced with no HR, indicating the anisotropic behaviour as a result of the scan track length.

- Through the introduction of hatch rotation, the isotropic mechanical and thermo-mechanical simulations were able accurately to predict the RS distribution; however, peak tensile stresses were over-predicted near the surfaces of the cubes.

- The thermo-mechanical ISM indicated the highest level of accuracy when applied to specimens with $90 \mathrm{HR}$, with all of the maximum stress differences being less than 150MPa for the $\sigma_{\mathrm{xx}}$ and $\sigma_{\mathrm{yy}}$ stress directions. However, this brought a large increase in computational cost with only a slight increase in accuracy.

- $\quad$ All of the simulation types were least accurate in determining the $\sigma_{\mathrm{zz}} \mathrm{RS}$; however, the average absolute stress differences for these values could be reduced through the incorporation of HR.

- $\quad$ Stress relaxation occurring towards the bottom surfaces and the bottom of the left side vertical faces of the cubes was not fully taken into account by the ISM.

\section{ACKNOWLEDGEMENTS}

Financial support from the Northwest University Additive Manufacturing Research Group (AMRG) and the Collaborative Programme for Additive Manufacturing is gratefully acknowledged. Further acknowledgement and thanks are given to the South African Nuclear Energy (NECSA) for the use of its neutron diffraction facilities.

\section{REFERENCES}

[1] T. D. Ngo, A. Kashani, G. Imbalzano, K. T. Q. Nguyen, and D. Hui, “Additive manufacturing (3D printing): A review of materials, methods, applications and challenges," Compos. Part B Eng., vol. 143, no. December 2017, pp. 172196, 2018, doi: 10.1016/j.compositesb.2018.02.012.

[2] Y. Lu, S. Wu, Y. Gan, T. Huang, C. Yuang, L. Junjie, and J. Lin, "Study on the microstructure, mechanical property and residual stress of SLM Inconel-718 alloy manufactured by differing island scanning strategy," Opt. Laser Technol., vol. 75, pp. 197-206, 2015, doi: 10.1016/j.optlastec.2015.07.009.

[3] J. L. Bartlett and X. Li, “An overview of residual stresses in metal powder bed fusion," Addit. Manuf., vol. 27, no. March, pp. 131-149, 2019, doi: 10.1016/j.addma.2019.02.020.

[4] M. Shiomi, T. Yamashital, and E. Materials, "Residual Stress within Metallic Model Made by Selective Laser Melting Process," CIRP Ann., vol. 53, no. 1, pp. 195-198, 2004, doi: 10.1016/S0007-8506(07)60677-5.

[5] T. Mukherjee, V. Manvatkar, and T. Debroy, "Mitigation of thermal distortion during additive manufacturing,"Scripta Materialia, vol. 127, pp. 79-83, 2017, doi: 10.1016/j.scriptamat.2016.09.001.

[6] V. A. Popovich, E. V Borisov, A. A. Popovich, V. S. Su, D. V Masaylo, and L. Alzina, "Functionally graded Inconel 718 processed by additive manufacturing : Crystallographic texture , anisotropy of microstructure and mechanical properties," Mater. Des., vol. 114, pp. 441-449, 2017, doi: 10.1016/j.matdes.2016.10.075..

[7] M. Balbaa, S. Mekhiel, M. Elbestawi, and J. Mclsaac, "On selective laser melting of Inconel 718 : Densi fi cation , surface roughness, and residual stresses," Mater. Des., vol. 193, no. 108818, 2020, doi: 10.1016/j.matdes.2020.108818.

[8] D. Du, A. Dong, D. Shu, G. Zhu, B. Sun, X. Li, and E. Lavernia, “Influence of build orientation on microstructure, mechanical and corrosion behavior of Inconel 718 processed by selective laser melting," 2019, doi: 10.1016/j.msea.2019.05.013.

[9] X. Wang, T. Keya, and K. Chou, "Build Height Effect on the Inconel 718 Parts Fabricated by Selective Laser Melting," Procedia Manuf., vol. 5, pp. 1006-1017, 2016, doi: 10.1016/j.promfg.2016.08.089.

[10] H. Ali, H. Ghadbeigi, and K. Mumtaz, "Effect of scanning strategies on residual stress and mechanical properties of selective laser melted Ti6Al4V," Mater. Sci. Eng. A., vol. 712, no. December 2017, pp. 175-187, 2018, doi: 10.1016/j.msea.2017.11.103.

[11] B. Cheng, S. Shrestha, and K. Chou, "Stress and deformation evaluations of scanning strategy effect in selective laser melting," Addit. Manuf., vol. 12, Part B, pp. 240-251, 2016, doi: 10.1016/j.addma.2016.05.007. 
[12] I. S. Munoz, T. Mishuroa, T. Thiede, M. Sprengel, A. Kromm, N. Nadammal, G. Nolze, R. Saliwan-Neumann, A. Evans, and G. Bruno, "The residual stress in as - built Laser Powder Bed Fusion IN718 alloy as a consequence of the scanning strategy induced microstructure," Sci. Rep., vol. 10, pp. 1-15, 2020, doi: 10.1038/s41598-020-71112-9.

[13] L. Li and S. Anand, "Hatch pattern based inherent strain prediction using neural networks for powder bed fusion additive manufacturing," J. Manuf. Process., vol. 56, no. March, pp. 1344-1352, 2020, doi: 10.1016/j.jmapro.2020.04.030.

[14] M. Bugatti and Q. Semeraro, "Limitations of the inherent strain method in simulating powder bed fusion processes," Addit. Manuf., vol. 23, no. June, pp. 329-346, 2018, doi: 10.1016/j.addma.2018.05.041.

[15] Q. Chen, X. Liang, D. Hayduke, J. Liu, L. Cheng, J. Oskin, R. Whitmore, and A. C. To, "An inherent strain based multiscale modeling framework for simulating part-scale residual deformation for direct metal laser sintering," Addit. Manuf., vol. 28, no. December 2018, pp. 406-418, 2019, doi: 10.1016/j.addma.2019.05.021.

[16] C. Li, J. F. Liu, X. Y. Fang, and Y. B. Guo, "Efficient predictive model of part distortion and residual stress in selective laser melting," Addit. Manuf., vol. 17, pp. 157-168, 2017, doi: 10.1016/j.addma.2017.08.014.

[17] R. Eberlein, T. Mayer, G. Brandel, and A. Schonenberger, "Simulation and validation of residual deformations in additive manufacturing of metal parts," Heliyon, vol. 6, no. e03987, 2020, doi: 10.1016/j.heliyon.2020.e03987.

[18] B. Vrancken, V. Cain, R. Knutsen, and J. Van Humbeeck, "Residual stress via the contour method in compact tension specimens produced via selective laser melting," Scr. Mater., vol. 87, pp. 29-32, 2014, doi: 10.1016/j.scriptamat.2014.05.016.

[19] T. Mishurova, S. Cabeza, T. Thiede, N. Nadammal, A. Kromm, M. Klaus, C. Genzel, C. Haberland, and G. Bruno, "The Influence of the Support Structure on Residual Stress and Distortion in SLM Inconel 718 Parts," Metall. Mater. Trans. A, vol. 49A, no. 7, pp. 3038-3046, 2018, doi: 10.1007/s11661-018-4653-9.

[20] J. L. Bartlett, B. P. Croom, D. Henkel, and X. Li, "Revealing mechanisms of residual stress development in additive manufacturing via digital image correlation," Addit. Manuf., vol. 22, no. April, pp. 1-12, 2018, doi: 10.1016/j.addma.2018.04.025.

[21] P. Pant, S. Proper, V. Luzin, S. Sjostrom, K. Simonsson, J. Moverare, S. Hosseini, V. Pacheco, and R. Peng, “Mapping of residual stresses in as-built Inconel 718 fabricated by laser powder bed fusion: A neutron diffraction study of build orientation influence on residual stresses," Addit. Manuf., vol. 36, no. 101501, 2020, doi: 10.1016/j.addma.2020.101501.

[22] P. Pant, S. Sjostrom, K. Simonsson, J. Moerare, S. Proper, S. Hossieni, V. Luzin, and R. Peng, "A Simplified Layerby-Layer Model for Prediction of Residual Stress Distribution in Additively Manufactured Parts," Metals (Basel)., vol. 11, no. 861, pp. 1-23, 2021.

[23] "Simufact additive: A simulation tool for distortion prediction in powder bed additive manufacturing," Jan. 2020, Accessed Jul. 13 2021. Available: http://www.mscsoftware.com/product/simufact-additive

[24] C. A. Schneider, W. S. Rasband, and K. W. Eliceiri, "NIH Image to ImageJ: 25 years of image analysis," Nat. Methods, vol. 9, no. 7, pp. 671-675, 2012, doi: 10.1038/nmeth.2089.

[25] M. R. Hill and D. V Nelson, "The localized eigenstrain method for determination of triaxial residual stress in weldS," ASME Publ. - PVP, vol. 373, pp. 397-403, 1998.

[26] M. R. Hill and D. V Nelson, "The inherent strain method for residual stress determination and its application to a long welded joint," ASME Publ. - PVP, vol. 318, pp. 343-352, 1995.

[27] K. Ravichandran, "Calibrating Inherent Strain for Additive Manufacturing An investigation of different subscale geometries,", M.S. Thesis, Department of Industrial and Materials Science, Chalmers University of Technology, Gothenburg Sweden, Accessed on: Oct, 20, 2021.[Online].Avaiable:

https: / /odr.chalmers.se/bitstream/20.500.12380/301798/1/Calibrating\%20Inherent\%20Strain\%20for\%20Additive\% 20Manufacturing.pdf

[28] X. Liang, L. Cheng, Q. Chen, Q. Yang, and A. To, “A Modified Method for Estimating Inherent Strains from Detailed Process Simulation for Fast Residual Distortion Prediction of Single-Walled Structures Fabricated by Directed Energy Deposition," Addit. Manuf., vol. 23, pp. 471-486, 2018, doi: 10.1016/j.addma.2018.08.029.

[29] A.-M. Bastus, "Numerical sensitivity analysis of residual stress and distortion in slective laser melting of 17-4 PH steel," M.S. Thesis, Mechanical Engineering, Montanuniversitat Leoben, Leoben, Accessed on: 20 Oct 2021 [Online]. Available: https://upcommons.upc.edu/bitstream/handle/2117/184014/numerical-sensitivity-study-of-residualstress-and-distortion-in-selective-laser-melting-of-17-4-ph-steel.pdf?sequence $=1$ \&isAllowed=y.

[30] A. M. Venter, P. R. van Heerden, D. Marais, and J. C. Raaths, "MPISI: The neutron strain scanner materials probe for internal strain investigations at the SAFARI-1 research reactor," Phys. B Condens. Matter, vol. 551 , no. November 2017, pp. 417-421, 2018, doi: 10.1016/j.physb.2017.12.011. 